\title{
Southeast Greenland high accumulation rates derived from firn cores and ground-penetrating radar
}

\author{
Clément MIÈGE, ${ }^{1}$ Richard R. FORSTER, ${ }^{1}$ Jason E. BOX, ${ }^{2,3}$ Evan W. BURGESS, ${ }^{1}$ \\ Joseph R. McCONNELL, ${ }^{4}$ Daniel R. PASTERIS, ${ }^{4}$ Vandy B. SPIKES ${ }^{5}$ \\ ${ }^{1}$ Department of Geography, University of Utah, Salt Lake City, UT, USA \\ E-mail: clement.miege@geog.utah.edu \\ ${ }^{2}$ Department of Geography, The Ohio State University, Columbus, OH, USA \\ ${ }^{3}$ Byrd Polar Research Center, The Ohio State University, Columbus, OH, USA \\ ${ }^{4}$ Desert Research Institute, Reno, NV, USA \\ ${ }^{5}$ Earth Science Agency, LLC, Scottsdale, AZ, USA
}

\begin{abstract}
Despite containing only $14 \%$ of the Greenland ice sheet by area, the southeastern sector has the highest accumulation rates, and hence receives $\sim 30 \%$ of the total snow accumulation. We present accumulation rates obtained during our 2010 Arctic Circle Traverse derived from three $50 \mathrm{~m}$ firn cores dated using geochemical analysis. We tracked continuous internal reflection horizons between the firn cores using a $400 \mathrm{MHz}$ ground-penetrating radar (GPR). GPR data combined with depth-age scales from the firn cores provide accumulation rates along a $70 \mathrm{~km}$ transect. We followed an elevation gradient from $\sim 2350$ to $\sim 1830 \mathrm{~m}$ to understand how progressive surface melt may affect the ability to chemically date the firn cores and trace the internal layers with GPR. From the firn cores, we find a $52 \%$ $\left(\sim 0.43 \mathrm{~m} \mathrm{w} . e . \mathrm{a}^{-1}\right)$ increase in average snow accumulation and greater interannual variability at the lower site than the upper site. The GPR profiling reveals that accumulation rates are influenced by topographic undulations on the surface, with up to $23 \%$ variability over $7 \mathrm{~km}$. These measurements confirm the presence of high accumulation rates in the southeast as predicted by the calibrated regional climate model Polar MM5.
\end{abstract}

\section{INTRODUCTION}

In recent decades, significant air and ocean warming has been observed in Greenland (e.g. Meehl and others, 2007; Levitus and others, 2009), causing mass loss to accelerate on the ice sheet by surface melting, runoff and ice discharge (e.g. Van den Broeke and others, 2009; Rignot and others, 2011). The current Greenland ice sheet mass loss is estimated to range from $191 \pm 23$ to $240 \pm 28 \mathrm{Gta}^{-1}$ by combining NASA's Ice, Cloud and land Elevation Satellite (ICESat) elevation measurements, firn compaction and modeled surface density (Sørensen and others, 2011). The Gravity Recovery and Climate Experiment (GRACE) mission provided an independent check that confirmed the Greenland ice sheet loss of $219 \pm 38 \mathrm{Gta}^{-1}$ for 2002-09 (J.L. Chen and others, 2011). In the last decade, about half of the mass loss is due to ice dynamics, and the rest is due to surface mass-balance processes (Van den Broeke and others, 2009). Surface mass balance for the Greenland ice sheet can be approximated by snowfall (accumulation) minus ablation, and its interannual variability over the 1957-2008 period is very large, with a standard deviation, $\sigma$, of $107 \mathrm{Gta}^{-1}$ (Ettema and others, 2009).

Accumulation is the only mass input to the Greenland ice sheet, and its magnitude, spatial and temporal distributions are poorly constrained, especially in the southeast sector (e.g. Burgess and others, 2010). Measurement uncertainty of the accumulation input to the ice sheet leads to uncertainty in the total mass budget of Greenland. The mass budget needs to be estimated in order to understand ice-sheet behavior, which is a critical question. Since accumulation may increase with future warming (e.g. Meehl and others, 2007), reducing uncertainty in ice-sheet accumulation and better estimating the total mass budget is also critical. Recently, for the 2007-09 time period, the southeast sector of the ice sheet has lost $172 \pm 44 \mathrm{Gta}^{-1}$, which is a large part of the total mass loss over the whole ice sheet (J.L. Chen and others, 2011). However, an increase in accumulation rates that could offset this mass loss has not yet been observed.

We present snow accumulation rates derived from new firn cores and ground-penetrating radar (GPR) measurements across poorly sampled areas of the southeastern Greenland ice sheet. The objectives of this study are to confirm the modeled high snow accumulation rates and to quantify the spatial and temporal variations in snow accumulation over the past 30 years. Below we introduce previous work on Greenland accumulation estimates and on GPR studies, which serve as the context for our study.

\subsection{Accumulation-rate measurements}

Accumulation rates over the Greenland ice sheet have been studied using a variety of methods. We discuss three of these, and highlight the need for additional in situ measurements in the southeast sector of the ice sheet. In the first method, accumulation maps are generated by interpolating in situ point measurements. Ice cores and snow pits, located in the upper accumulation area, are the most common observations. Along the coast of Greenland, the Danish Meteorological Institute maintains meteorological stations to measure accumulation from solid precipitation minus evaporation. Benson (1962) and Ohmura and Reeh (1991) produced initial snow accumulation maps from these limited observations. Since then the spatial and temporal resolution of these accumulation maps has been increased using updated ice-core data, an increasing number of coastal weather 
stations, and more sophisticated interpolation techniques (Ohmura and others, 1999; Calanca and others, 2000; Bales and others 2001, 2009; McConnell and others, 2001; Cogley, 2004). In the second method, regional climate models are used to simulate recent climate (typically since 1958 because of the availability of reliable reanalysis fields) of the ice sheet and also provide accumulation maps (Fettweis, 2007; Hines and Bromwich, 2008; Ettema and others, 2010; Lucas-Picher and others, 2012). However, all the different modeled snow accumulation outputs do not fully agree, and the lack of in situ measurements in the southeast sector does not yet allow model comparison and validation (Rae and others, 2012). For example, the Regional Atmospheric Climate Model (RACMO2; Ettema and others, 2009) modeled higher accumulation in southeast Greenland compared to estimates from Box and others (2006) using the Fifth Generation Mesoscale Model modified for polar climates (Polar MM5), or to Fettweis (2007) using the Modèle Atmosphérique Régional (MAR). A hybrid technique uses the discrepancies between regional climate model outputs and in situ measurements to generate correction factors to produce calibrated accumulation maps (Box and others, 2006; Burgess and others, 2010). In the third method, accumulation maps are reconstructed using meteorological reanalysis, including ERA-40 (e.g. Hanna and others, 2006), 20CR (e.g. Hanna and others, 2011) and ERA-Interim (e.g. L. Chen and others, 2011).

The southeast sector of the ice sheet represents only $14 \%$ of the total ice-sheet area and accounts for $31 \%$ of total accumulated mass and $32 \%$ of annual accumulation variability (Burgess and others, 2010). Only $2 \%$ of the available firn-core data of the Greenland ice sheet are found in the southeast sector, but no firn-core data are found below $2000 \mathrm{~m}$ elevation, where higher accumulation rates are predicted: $>2$ mw.e. $\mathrm{a}^{-1}$ (Burgess and others, 2010) and reaching up to $5 \mathrm{~m}$ w.e. $\mathrm{a}^{-1}$ (Rae and others, 2012). It is difficult to estimate accumulation close to the southeast Greenland coast, where orographic precipitation dominates and topography is complex (e.g. Burgess and others, 2010; Lucas-Picher and others, 2012). These studies emphasized the need for in situ measurements to constrain climate models in this sector. In addition, Hanna and others (2011) noted the lack of validation data for climate models and showed that uncertainties in southeast Greenland accumulation are greatest where accumulation rates are highest, and where both accumulation and topographic gradients are significant.

\subsection{Ground-penetrating radar (GPR)}

GPR allows us to capture spatial variability in accumulation over distances of tens to hundreds of $\mathrm{km}$. Small-scale spatial variability in accumulation $(\sim 5-10 \mathrm{~km})$, mostly due to snow redistribution and surface undulations, is not captured in point measurements from cores and is not taken into account in regional climate models with large gridcells $(\sim 5-25 \mathrm{~km})$. The spatial variability of snow accumulation can be observed in GPR transects that show continuous internal reflection horizons (IRHs) (e.g. Arcone and others, 2004, 2005a; Dunse and others 2008). IRHs at relatively shallow depths $(<50 \mathrm{~m})$ are primarily due to density contrasts (e.g. Eisen and others, 2003; Arcone and others, 2005a). The isochronous nature of IRHs has been confirmed using the depth-age scale from firn cores located at both ends of the GPR profile (Spikes and others, 2004; Eisen and others, 2006).
In the southeast sector of the ice sheet, for an elevation range between $\sim 1840$ and $\sim 2350 \mathrm{~m}$, two major snow facies are found in our GPR profile. At elevations above $2000 \mathrm{~m}$, the dry-snow facies is represented with no or little melt ( $\sim 1-3 \mathrm{~cm}$ melt layers). At lower elevation, the percolation facies is found where surface snow melts and travels downward through the snowpack until it refreezes (e.g. Benson, 1962), which likely produces vertical ice pipes and horizontal ice layers. Recent GPR studies in West Greenland documented the presence of ice layers within the firn (e.g. Parry and others, 2007; Dunse and others 2008; Brown and others, 2011). These features complicate tracing of continuous IRHs in the firn depending upon melt intensity, spatial scale and radar frequency. Dunse and others (2008), using GPRs with frequency of 500 and $800 \mathrm{MHz}$, were able to track IRHs down to $10 \mathrm{~m}$ depth. Brown and others (2011) found no correlation between IRHs and firn stratigraphy in the higher-elevation part of the percolation zone in West Greenland and assumed the IRHs were multi-annual features (2-10 years) in the lower part of the percolation zone. These studies highlight the challenges in identifying isochronous IRHs from GPR profiles, and tracking them over many kilometers. However, all of these studies were conducted in regions where accumulation rates are low compared to southeast Greenland. In the southeastern sector, high accumulation rates can prevent multi-annual melt features from dominating the GPR reflections at shallow depths $(<50 \mathrm{~m})$.

\section{ARCTIC CIRCLE TRAVERSE 2010}

Our study took place in the southeast sector of the Greenland ice sheet (Fig. 1), where few field investigations have been reported, mostly due to high accumulation rates in this region that discouraged long-term climate-data collection. We conducted the $500 \mathrm{~km}$ Arctic Circle Traverse 2010 (ACT-10) by snowmobile, starting at the Dye- 2 station (now called 'Raven') and moving toward the southeast icesheet margin. The data presented here were collected from 26 April to 9 May 2010, prior to surface melting that could have confounded propagation of the radar signal into the subsurface. ACT-10 repeated and extended the first ACT from 2004, which crossed the ice divide at the location 'Saddle' (Spikes and others, 2007). In 2010, three $50 \mathrm{~m}$ firn cores were collected (Table 1), and surface-based GPR was used to track continuous IRHs between the core sites. Our transect is located $>110 \mathrm{~km}$ away from the open ocean. Surface mean temperature is $-19.3 \pm 0.2^{\circ} \mathrm{C}$ (Box and others, 2009), obtained from the NASA-SE weather station which is located $\sim 55 \mathrm{~km}$ north of ACT10-C (see Fig. 1). The mean wind speed recorded by the NASA-SE weather station is $5.5 \mathrm{~m} \mathrm{~s}^{-1}$, and its dominant direction has an azimuth of $315^{\circ}$ (Steffen and Box, 2001), which is characteristic of the katabatic wind flow regime that is prevalent in this sector of the ice sheet. While GPR data were collected on the return segment of the traverse from ACT10-A to Dye-2 $(250 \mathrm{~km})$, this study focuses on the lowest-elevation eastern segments between ACT10-A and ACT10-C (Fig. 1) where the accumulation rates have been predicted to be the highest (Burgess and others, 2010; Rae and others, 2012).

The ACT-10 traverse route covered a relatively slowmoving portion of the ice sheet. Observed surface velocities, for 2008-09, are in the 50-100 $\mathrm{m} \mathrm{a}^{-1}$ range, between ACT10-C and ACT10-A (Rignot and Mouginot, 2012). We 


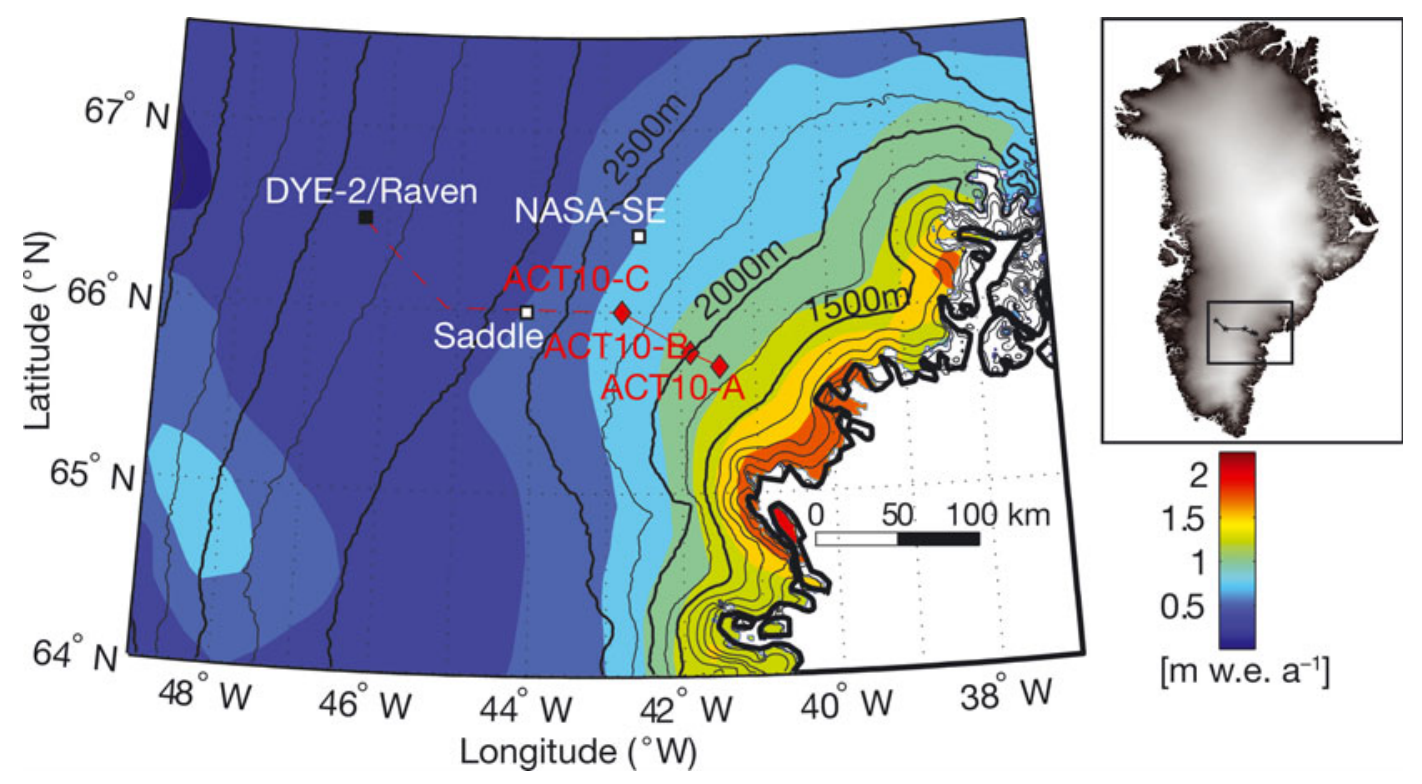

Fig. 1. Study site in southeast Greenland with the ACT-10 route, which started at Dye-2 (black square). The red solid line represents the $70 \mathrm{~km}$ GPR data presented in this paper. The red dashed line represents the rest of the traverse route, which is not discussed here. The red diamonds are the locations of firn cores drilled as part of this project. The black lines are elevation contours with $250 \mathrm{~m}$ spacing from Bamber and others (2001). NASA-SE and Saddle weather stations are represented by white squares. The background is the mean (1958-2008) accumulation rates (m w.e. $\mathrm{a}^{-1}$ ) modeled by Burgess and others (2010).

determined the flowline direction based on surfaceelevation contours from the digital elevation model produced by Bamber and others (2001); our GPR profile is approximately parallel to the current flow direction. The average ice thickness along the ACT10-A to ACT10-C transect is $1520 \pm 4.5 \mathrm{~m}$ (Leuschen and Allen, 2011). Here we assume that the observed structure of the IRHs is only due to variations in accumulation, and not due to ice dynamics. This simplification can be made because of the high accumulation in this area and the minimal internal deformation at these depths corresponding to a short period of time analyzed (1995-2010).

\section{METHODS}

\subsection{Firn cores}

Three $82 \mathrm{~mm}$ diameter firn cores (ACT10-A, -B, -C) were drilled with an ECLIPSE drill (designed by Icefield Instruments Inc.), starting $2 \mathrm{~m}$ below the surface in a trench to allow room for core-barrel clearance. The upper $2 \mathrm{~m}$ were sampled manually using the core barrel. In the field, $\sim 1 \mathrm{~m}$ core sections were labeled and bagged before being shipped frozen to the Desert Research Institute Ultra-trace Chemistry Laboratory. The core sections were then processed and analyzed for a broad range of elements and chemical species, which were used to develop a precise depth-age relationship and annual accumulation rates (Table 1). First, the cores were cut into rectangular samples, each $\sim 1 \mathrm{~m} \times$ $\sim 35 \mathrm{~mm} \times \sim 35 \mathrm{~mm}$. The samples from each site were weighed, used for the depth-density profile and then analyzed using a continuous flow analysis system with an effective depth resolution of $\sim 10 \mathrm{~mm}$ (McConnell and others, 2002; Banta and McConnell, 2007; McConnell and others, 2007). This system is composed of two highresolution inductively coupled plasma mass spectrometers and a number of fluorimeters, spectrophotometers and other instruments (Banta and McConnell, 2007). Indicators of continental dust $(\mathrm{Al}, \mathrm{Mg}, \mathrm{Ca}, \mathrm{Fe})$, sea salts $(\mathrm{Na}, \mathrm{Mg}, \mathrm{Ca}, \mathrm{S})$, industrial pollution $(\mathrm{Pb}, \mathrm{Tl}, \mathrm{Cd}, \mathrm{S}$, nitrate), explosive volcanism (S), biomass burning (black carbon, ammonium, nitrate) and atmospheric photochemistry (hydrogen peroxide $\left.\left(\mathrm{H}_{2} \mathrm{O}_{2}\right)\right)$ are used for annual-layer counting since most, if not all, of the chemical proxies show pronounced annual cycles in concentration. In regions with high accumulation rates such as southeast Greenland, $\mathrm{H}_{2} \mathrm{O}_{2}$ is often the preferred

Table 1. ACT-10 firn cores. Mean annual accumulation rates are given with one standard deviation for firn cores and for calibrated Polar MM5, representing the range of the annual values in each time series. Calibrated Polar MM5 and firn-core mean accumulation rates are calculated from the bottom age of each firn core until 2008

\begin{tabular}{|c|c|c|c|c|c|c|c|}
\hline \multirow[t]{3}{*}{ Firn core } & \multirow[t]{3}{*}{ Lat. (N) } & \multirow[t]{3}{*}{ Long. (W) } & \multirow{3}{*}{$\begin{array}{c}\text { Elevation } \\
\text { ma.s.l. }\end{array}$} & \multirow{3}{*}{$\begin{array}{c}\text { Length } \\
\text { m }\end{array}$} & \multicolumn{2}{|c|}{ Mean accumulation } & \multirow[t]{3}{*}{ Time-span } \\
\hline & & & & & Firn cores & Polar MM5 & \\
\hline & & & & & m w.e. $a^{-1}$ & m w.e. $a^{-1}$ & \\
\hline ACT10-A & $65^{\circ} 41^{\prime}$ & $41^{\circ} 28^{\prime}$ & 1825 & 47 & $1.26 \pm 0.731$ & $1.19 \pm 0.298$ & 1985-2010 \\
\hline ACT10-B & $65^{\circ} 46^{\prime}$ & $41^{\circ} 52^{\prime}$ & 1999 & 49 & $1.09 \pm 0.519$ & $1.08 \pm 0.241$ & 1980-2010 \\
\hline
\end{tabular}




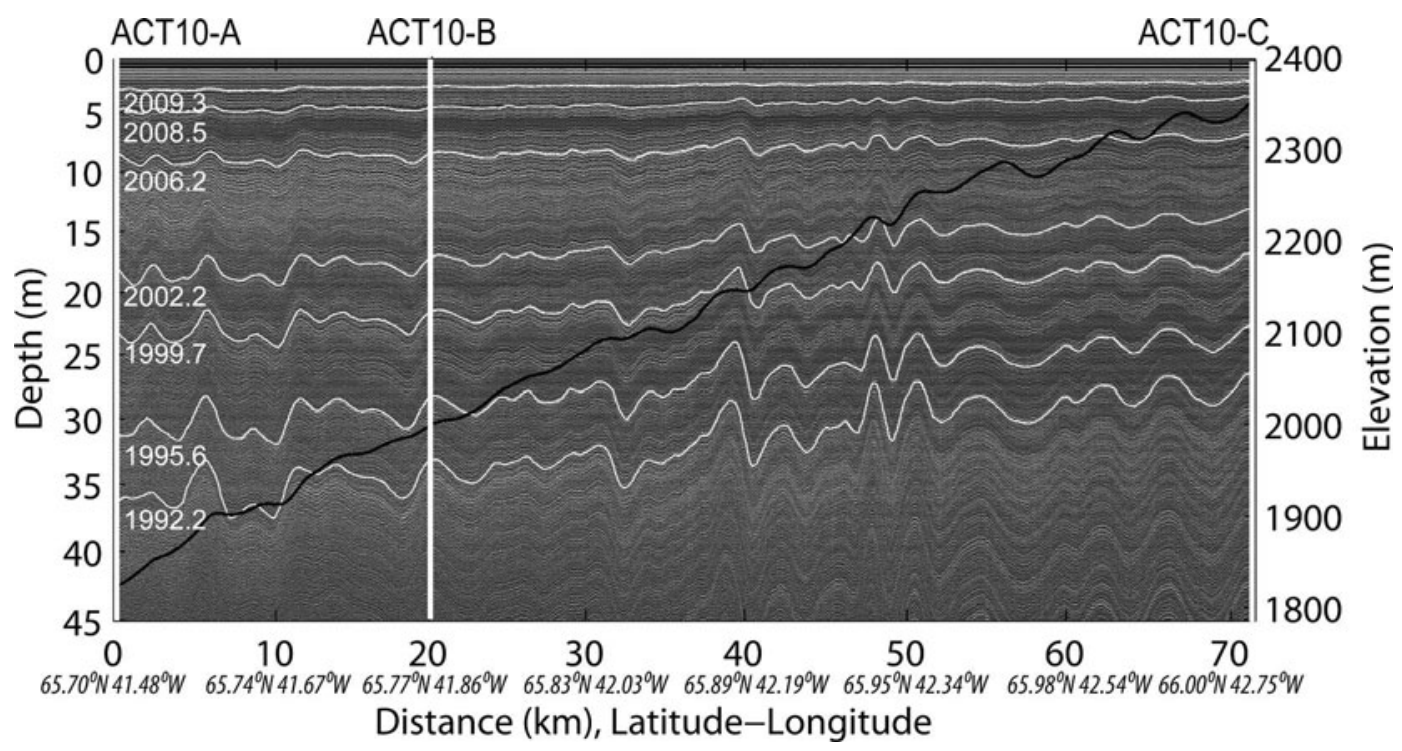

Fig. 2. GPR profile between ACT10-A and ACT10-C. A total of seven different IRHs (white dashed lines) are tracked for the entire radar profile. Each isochronous layer is dated using the depth-age scale at the three core sites, and an averaged fractional age is obtained (white characters). Firn-core sites are represented by white vertical lines. ACT10-A and ACT10-C are on the left and right side of the profile, respectively. The depth scale represented on the vertical axis is calculated from the TWT-depth conversion (see Section 3.3) for the ACT10-A firn core. The black line corresponds to the elevation profile associated with the GPR profile.

proxy because of its distinctive annual concentration cycle and consistent midwinter minimum (McConnell and Bales, 2004). Here we relied primarily on the annual $\mathrm{H}_{2} \mathrm{O}_{2}$ cycle for annual dating but secondarily used chemical proxies to confirm annual-layer identification in the few cases of unclear $\mathrm{H}_{2} \mathrm{O}_{2}$ cycles. The most commonly used secondary proxy was the non-sea-salt sulfur to sodium ratio (nssS/ $\mathrm{Na}$ ), which showed a very strong annual cycle due to the occurrence of anticorrelated annual cycles in the nssS and $\mathrm{Na}$ species. Over the southeast sector of the ice sheet, extensive summer melting, revealed by the presence of thick ice layers $(>10 \mathrm{~cm})$, has the potential to disrupt firn stratigraphy. Accumulation from one year may percolate down and refreeze in a different annual layer, confounding water equivalence measurements using annual glaciochemical signals. However, in our study area, accumulation rates are generally high enough and percolating surface meltwater penetrates less than the full depth of a given year's accumulation. Because of the multiple chemical parameters available and the high snow accumulation rate, the maximum dating uncertainty is estimated to be 1 year.

An annual depth-age relationship is deduced from chemistry-peak identification and, a posteriori, is used to test for isochronal accuracy in the GPR profile between two firn cores. Since the $\mathrm{H}_{2} \mathrm{O}_{2}$ peak does not occur at the exact beginning of the year, a fractional year, with 0.1 year resolution, is required to capture the full variability in snow accumulation. To convert the snow depth to accumulation at each core site for each year, an exponential function is fit to the density profile (see Section 3.3 for further details on density analysis).

\subsection{GPR and GPS data}

The GPR system used for ACT-10 was the Geophysical Survey Systems, Inc. (GSSI) SIR-3000 controller and a $400 \mathrm{MHz}$ center frequency antenna, with an $800 \mathrm{MHz}$ bandwidth. The estimated vertical resolution for the dry Antarctic firn is $\sim 35 \mathrm{~cm}$ (Arcone and others, 2004; Spikes and others, 2004), which is less than the thickness between two annual layers in our study area. The sampling interval was set at 6 traces s ${ }^{-1}, 2048$ vertical samples per trace. As the expedition moved across the ice sheet at $\sim 3 \mathrm{~m} \mathrm{~s}^{-1}$, the deduced trace spacing is $\sim 0.5 \mathrm{~m}$. In addition, to increase the signal-to-noise ratio, an initial stacking of 6 traces was performed. A time-dependent gain was used to compensate for signal attenuation by the firn. The time window was 500 ns, with 2048 samples trace $^{-1}$, giving a sampling interval of $\sim 0.24 \mathrm{~ns}$, with an average penetration depth of $\sim 45 \mathrm{~m}$.

In post-processing, additional horizontal spatial averaging was done by stacking 8 traces, in addition to the original stacking of 6 traces in the field; thus each final trace has been averaged from 48 initial traces. This spatial averaging aims to increase the signal-to-noise ratio and minimize the influence of layer variations and cm-scale vertical ice layers present in the percolation zone, as described by Humphrey and others (2012).

Coupled to the GPR measurements, a Trimble R7 geodetic-quality GPS receiver was used to track the location of the GPR profile every $5 \mathrm{~s}$, corresponding to one point for $\sim 15 \mathrm{~m}$ (for a travel speed $\sim 3 \mathrm{~m} \mathrm{~s}^{-1}$ ). The GPS receiver was mounted on the snowmobile towing the GPR sled. Each GPR trace is georeferenced using processed GPS data that have been interpolated based on the time when GPR data collection began (obtained from the kinematic GPS receiver) and the trace acquisition rate. GPS data processing was done using the Canadian Spatial Reference Service Precise Point Positioning (CSRS-PPP). This processor uses GPS orbit and clock information to enhance positioning precisions in the International Terrestrial Reference Frame (ITRF) via a kinematic processing mode. Uncertainties in the GPS positions are given within one standard deviation for the ACT10-A to ACT10-C transect. The maximum standard deviations are $0.07 \mathrm{~m}$ for latitude and longitude ( $\sim 0.02 \mathrm{~m}$ on average) and $0.22 \mathrm{~m}$ for elevation ( $\sim 0.06 \mathrm{~m}$ on average).

\subsection{Accumulation-rate calculation}

Depth-age profiles from three firn cores collected along the GPR profile (Fig. 2) are used to confirm that the IRHs are 


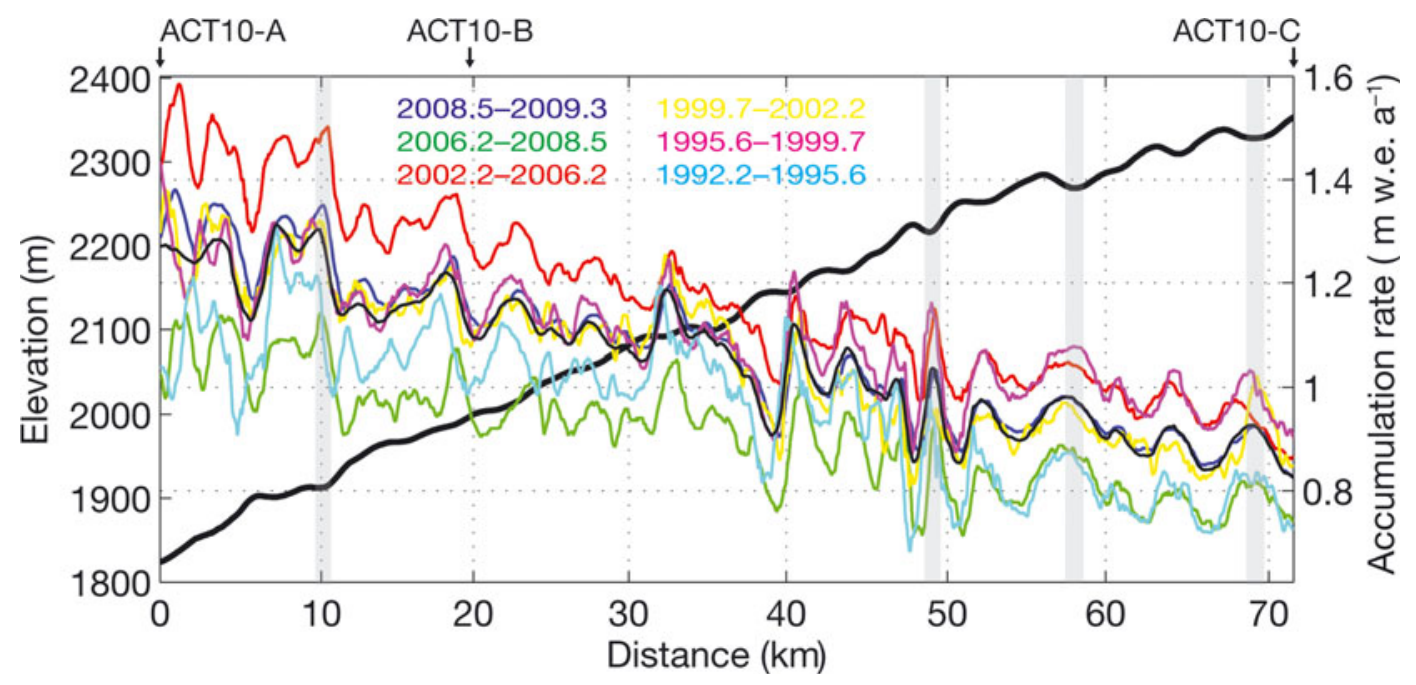

Fig. 3. Temporal and spatial variability in snow accumulation rates for six time periods revealed by GPR profiling between firn cores ACT10$\mathrm{A}$ and ACT11-C; the thin black line represents the averaged accumulation for the whole time period 1992.2-2009.3. The thick black line represents the elevation profile. The four gray-shaded vertical bars illustrate four examples, along the GPR profile, of the presence of highaccumulation peaks located in topographic depressions, highlighting the role of wind redistribution of snow.

isochrones (see Section 4.3 for details on isochronal accuracy). Only the most prominent IRHs, which were the easiest to trace in the GPR profile, were used for digitizing (Fig. 2). Manual layer picking was preferred because it provided better operator control when IRHs were laterally discontinuous. While manually picking, if a short lateral discontinuity $(<100 \mathrm{~m})$ was observed in the GPR profile, the operator used the two IRHs located directly above and below the tracked IRH as a guide to estimate the tracked IRH depth. Three possible explanations for the partial disruption of an IRH are: (1) Topographic undulations on the surface of the ice sheet may result in more pronounced folds at depth (Fig. 2), which can induce a two-way-travel time (TWT) phase delay of as much as half the wavelength for only a $0.4^{\circ}$ incidence angle for a given dip that reduces return strengths and causes destructive interference (Spikes and others, 2004). (2) The presence of ice layers, due to heterogeneous meltwater infiltration, may disrupt the lateral continuity of an IRH (see Section 4.2 for details). (3) The surface roughness can cause vertical artifacts (e.g. when the radar sled lost contact with the snow surface due to sastrugi, making the IRHs more difficult to track).

For an individual digitized radar horizon, several steps are required to obtain accumulation rates. At each firn-core site, the conversion of the radar TWT to distance below the surface is computed based on the core-density profile, through the relationship between velocity in the firn, $v_{\mathrm{f}}$, and firn density profile, $\rho(z)$ (Kovacs and others, 1995):

$$
\begin{gathered}
v_{\mathrm{f}}=c / \sqrt{\varepsilon^{\prime}} \\
\varepsilon^{\prime}=(1+0.845 \rho(z))^{2}
\end{gathered}
$$

where $c$ represents the speed of light in a vacuum, and $\varepsilon^{\prime}$ is the real part of the dielectric constant (permittivity).

The density profiles for the ACT-10 firn cores (Fig. 4) were derived from $\sim 1 \mathrm{~m}$ sections of the firn core (Section 3.1). We used an exponential fit to smooth and interpolate the density profile with depth:

$$
\rho(z)=\rho_{\mathrm{s}}+\alpha_{1} \mathrm{e}^{\left(\beta_{1} z\right)}+\alpha_{2} \mathrm{e}^{\left(\beta_{2} z\right)}
$$

where $\rho_{\mathrm{s}}$ is the density at the surface, $\alpha$ and $\beta$ are the fitting parameters and $z$ is the depth of the profile (Hörhold and others, 2011).

This fitted density profile is used for the TWT-depth conversion. Estimated snow depth for the radar signal is known at each core site and then linearly interpolated along the transect for each radar trace. To account for all three firn cores, we made two linear interpolations of the density profile, one between ACT10-A and ACT10-B and the second between ACT10-B and ACT10-C.

To determine the snow accumulation rate between two time periods, the depth of the upper horizon is subtracted from the depth of the lower horizon. The calculated snow thickness is then converted to a water equivalent depth using the interpolated density profile for each trace.

For defining each time period, absolute ages are assigned to an IRH from the three firn cores' depth-age scale. A conventional way to express the age of a tracked isochrone is to use the calendar year, which is reasonable in areas with low accumulation where isochrones are closer together (e.g. Spikes and others, 2004). In the southeast sector of the ice sheet, high accumulation rates allow us to express the age of each IRH in fractional years, increasing the precision of the accumulation-rate calculations. The GPR-derived annual accumulation rates depend primarily on the age of each tracked IRH. The estimated seasonality (fractional year) for different IRHs (Fig. 2) is not consistent from one horizon to another, varying from 0.2 to 0.7 years.

\section{RESULTS}

\subsection{GPR-derived accumulation rates}

Mean accumulation rates, derived from the firn cores, at each core site are 1.26, 1.09 and $0.83 \mathrm{~m}$ w.e. $\mathrm{a}^{-1}$ for ACT10A, ACT10-B and ACT0-C, respectively (Table 1). They are in agreement with the accumulation rates estimated by the calibrated Polar MM5 on the pixel corresponding to each core site (Table 1). Accumulation rates are calculated along the traverse from ACT10-A to ACT10-C, from the radar profile (Fig. 2) over different time periods (Fig. 3). They are 
smoothed to remove digitizing noise with a moving-average filter that was 20 traces wide. The accumulation rates presented for each period highlight an increasing trend in accumulation as elevation decreases, closer to the southeast ice margin. On average, a $52 \%$ increase in accumulation $\left(+0.43 \mathrm{~m}\right.$ w.e. $\left.\mathrm{a}^{-1}\right)$ is observed along the $70 \mathrm{~km}$ line between ACT10-C and ACT10-A for the 1992.2-2008.5 time period. The spatial variability in accumulation rates over this period has a standard deviation of 0.13 mw.e. $\mathrm{a}^{-1}$. A maximum local spatial variability in accumulation is found over a $7 \mathrm{~km}$ distance, with $0.24 \mathrm{mw}$.e. $\mathrm{a}^{-1}$ representing $23 \%$ of the annual mean (Fig. 3). As for temporal variability, an increase in accumulation may be expected in recent decades due to the increase in surface temperature (Box and others, 2013). However, we found no significant trend in accumulation rate from the firn cores over their respective time periods spanning the last $25-35$ years.

The wide range ( $\sim 0.26 \mathrm{~m}$ w.e. $\mathrm{a}^{-1}$ on average) of accumulation rates between the different time periods (Fig. 3) is mainly due to the presence or absence of an anomalous accumulation year. For example, 2003 is known to be a high-accumulation year (Box and others, 2005). The high accumulation over the 2002.2-2006.2 period is primarily driven by the anomalously high accumulation of 2003. In contrast, the 2006.2-2008.5 period is the lowestaccumulation period.

\subsection{Influence of ice layers}

Firn-core dating and GPR-derived accumulation rates are challenged by the increase in surface melt as meltwater penetrates the firn layer and refreezes. For the firn-core dating, at core sites such as ACT10-A (1825 m), accumulation rates are high $\left(1.26 \mathrm{~m}\right.$ w.e. $\left.\mathrm{a}^{-1}\right)$ and meltwater penetrates less $(\sim 20 \%)$ than the full depth of the present year's accumulation. For the IRH tracking on the GPR profile, the spatial variation of the density is difficult to estimate in the percolation zone because of heterogeneous water infiltration at small scales $(\sim 1-5 \mathrm{~m})$ (Humphrey and others, 2012). The presence of thicker ice layers at lower elevation (i.e. ACT10-A) is illustrated in Figure 4 where the $\sim 1$ m density measurements deviate most from the exponential fit. It becomes more difficult to track IRHs at greater depths (35$45 \mathrm{~m})$ as the surface elevation decreases and thicker ice layers become more common. By contrast, near ACT10-C we find more laterally homogeneous IRHs with few ice layers (Fig. 2). Understanding how firn stratigraphy affects the GPR signal is beyond the scope of this study, even if it remains an important upcoming challenge while mapping annual accumulation rates. These issues have been discussed for West Greenland by Brown and others (2011).

\subsection{Uncertainty estimates}

Different sources of uncertainty affect the estimation of the IRH depth and therefore the estimation of GPR-derived accumulation rates:

1. The vertical density profile at each core site is estimated from the mass of $\sim 1 \mathrm{~m}$ firn-core segments (Fig. 4). To avoid bias from a single core segment dominated by ice layers, we use an exponential fit to the density profile. A fitted density profile is needed especially at lowerelevation sites where intense melt layers are interspersed with lower-density firn, producing a sporadic depthdensity series (Fig. 4). The lowest correlation coefficient

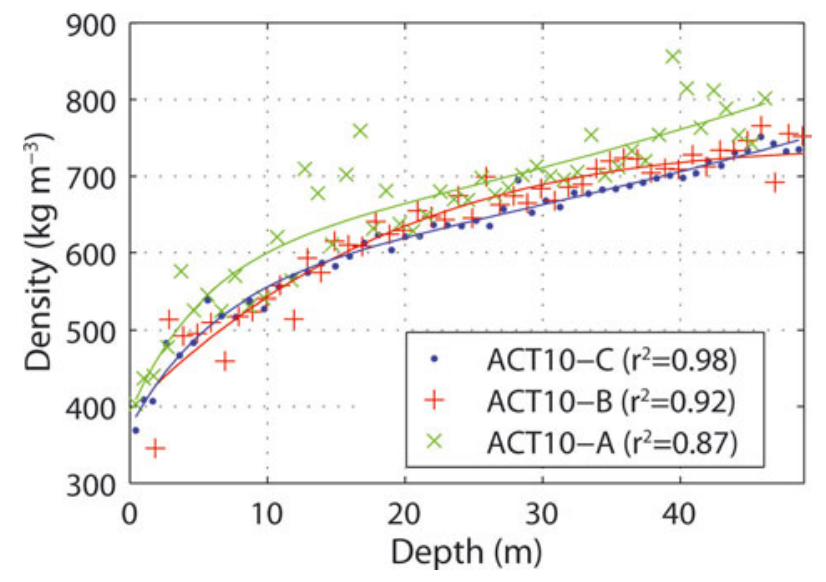

Fig. 4. Approximately $1 \mathrm{~m}$ density measurements made at each firncore site associated with colored lines representing the exponential fit. Fitted-density profiles are used for the TWT-depth conversion and accumulation-rate estimation in water equivalent (Section 3.3). Correlation coefficients, $r^{2}$, are associated for each firn-core site. Lower correlation coefficients indicate that short-scale density fluctuations increase.

of determination, $r^{2}$, between the exponential fit and the density-depth data is 0.87 at ACT10-A. The root-meansquare errors (RMSEs) for ACT10-A, ACT10-B and ACT10-C are $37.63,26.12$ and $12.21 \mathrm{~kg} \mathrm{~m}^{-3}$, respectively. A higher RMSE is expected for the presence of thick ice layers, with the original data deviating more from the fitted profile. Using an averaged RMSE $\left(25.3 \mathrm{~kg} \mathrm{~m}^{-3}\right)$, deviating at $4 \%$ from an averaged density, we obtain an average depth uncertainty of $\pm 24 \mathrm{~cm}$ from the surface to the depth of the deepest tracked IRH ( $35 \mathrm{~m})$.

2. In addition to the vertical exponential interpolation of density, an uncertainty is introduced while interpolating the density profile horizontally between two core sites. Snow stratigraphy and implied density are spatially variable at a meter scale, specifically in the percolation zone with the presence of heterogeneous infiltration forming ice layers and potential vertical channels by refreezing. By interpolating the density profile between two firn-core sites and stacking radar traces, the uncertainties are minimized. While comparing the fitted density profiles, the maximum standard deviation obtained is $31.18 \mathrm{~kg} \mathrm{~m}^{-3}$ between the ACT10-A, ACT10-B and ACT10-C fitted density profiles, yielding an average depth uncertainty of $\pm 28 \mathrm{~cm}$.

3. Layer picking and digitizing are performed manually, making the uncertainty difficult to quantify. Most of the IRHs observed comprise distinct wavelets with consistent phase polarity sequence: negative/positive/negative, corresponding to a 1.5 wavelet cycle (Arcone and others, 2005b). Deduced from the 1.5 cycle wavelet length, the GPR vertical resolution (separation of two IRHs) is $\sim 35 \mathrm{~cm}$ for the dry polar firn, with the wavelet response characterizing a single interface (Arcone and others, 2004). Along the ACT-10 transect, assuming that we are tracking the same IRH, the maximum 1.5 cycle wavelet lengths were $\sim 10$ vertical samples, $\sim 2.5 \mathrm{~ns}$ or $\sim 25 \mathrm{~cm}$, which is less than the $35 \mathrm{~cm}$ vertical resolution of the GPR. Ideally, the high accumulation rates in this area create sufficient vertical separation between annual layers that it becomes possible to track an IRH for most 


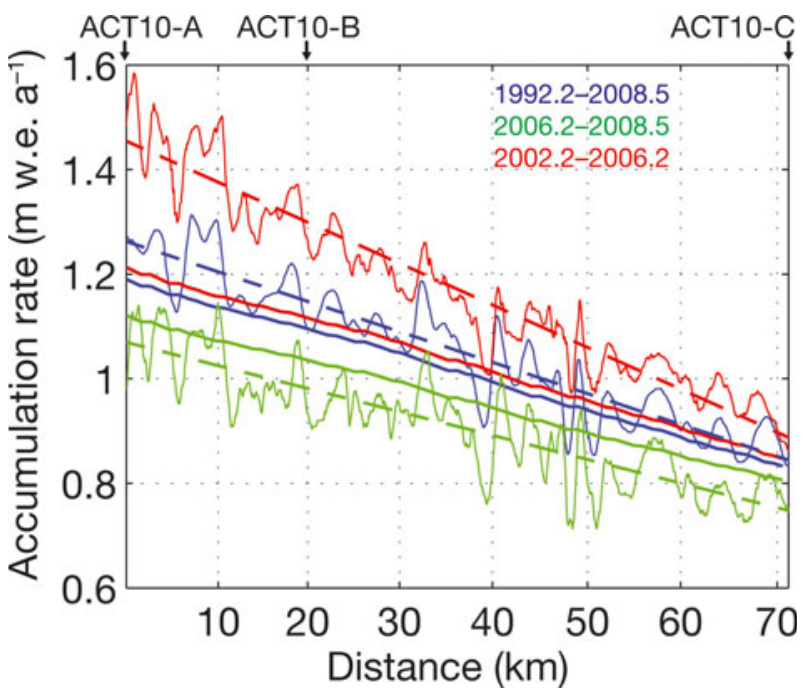

Fig. 5. Comparison between calibrated Polar MM5 (solid line) and accumulation rates derived from GPR (solid curves), along the GPR transect, for three different time periods, showing the accumulationrate variability. The periods chosen are the lowest (green) and highest (red) mean accumulation rates and the long-term average (blue). A linear fit (dashed line) is added for each period. The same time-span is used for calibrated Polar MM5 and GPR accumulation rates.

years. Even for the lower-accumulation site, the minimum annual firn layer thickness is $73.2 \mathrm{~cm}$, more than twice the vertical resolution of the GPR.

4. The age of an IRH is given at \pm 1 year from the firn-core chemistry dating. Then, despite this 1 year uncertainty in the absolute age, the isochronal accuracy of the IRHs is determined at the three ACT-10 core sites. The age of a continuous IRH is determined at each end of the radar profile, using the depth-age scales from the firn cores. The difference between the two years at each side of the radar profile (ACT10-A and ACT10-C) is calculated to give the precision of this isochronal tracking. The firn core between the two end points (ACT10-B) is used to confirm the result. The mean difference of the IRHs tracked for this GPR profile is \pm 0.14 years, with a maximum difference of 0.37 years, indicating that the IRHs are continuous and isochronal.

Finally, we estimate an average total depth uncertainty of $37 \mathrm{~cm}$ from the density vertical uncertainty (point 1 above) and the density horizontal uncertainty (point 2 above), using an orthogonal error propagation law, giving a $\sim 20 \%$ $( \pm 0.23 \mathrm{~m}$ w.e.) uncertainty in the GPR-derived accumulation rates for an averaged density $\left(640 \mathrm{~kg} \mathrm{~m}^{-3}\right)$. We did not include the core-dating uncertainty in this estimate, given the fact that each tracked IRH ends up with almost the same age (point 4 above) at the three firn-core sites along the profile and we are estimating the uncertainty of the accumulation rates derived from the technique of GPR interpolation between dated cores.

\section{DISCUSSION}

\subsection{Comparison with a regional climate model}

The ACT-10 accumulation rates are compared to modeled accumulation-rate output from Polar MM5, which was calibrated to existing firn-core data by Burgess and others
(2010). Calibrated Polar MM5 is favored in this study because it accounts for orographic precipitation that other modeled accumulation outputs underestimate (Burgess and others, 2010). The gridcells closest to the traverse line are used to produce an accumulation profile between ACT10-A and ACT10-C. Here we focus on two IRH intervals with low and high accumulation rates (years 2006.2-2008.5 and years 2002.2-2006.2, respectively) and an interval from the bottom IRH to the surface to provide a long-interval average accumulation record (years 1992.5-2008.2). These three periods show spatial and temporal differences in accumulation from the GPR profile (Fig. 5). For the 1992.5-2008.2 period, calibrated Polar MM5 accumulation rates are in agreement with our fitted GPR-derived accumulation rates (Fig. 5). However, the $24 \mathrm{~km}$ grid resolution of the model does not resolve the $\sim 10 \mathrm{~km}$ and smaller-scale variation in accumulation. Examining a shorter period from 2002.2 to 2006.2, the calibrated Polar MM5 underestimated accumulation by $\sim 20 \% \quad\left(\sim 0.24 \pm 0.16 \mathrm{mw}^{2}\right.$.e. $\left.\mathrm{a}^{-1}\right)$ at the highestaccumulation (and lowest-elevation) site (Fig. 5). The linear fit to the ACT-10 accumulation is steeper than the fit to calibrated Polar MM5. We think this is a consequence of the limited horizontal resolution of Polar MM5 $(24 \mathrm{~km})$ and/or the calibration methods used by Burgess and others (2010). However, for the period 2006.2-2008.5, calibrated Polar MM5 overestimates accumulation. The maximum RMSE associated with the GPR-derived results is $0.17 \mathrm{mw}$.e. $\mathrm{a}^{-1}$ for the period 2002.2-2006.2. This value is in agreement with the calibrated Polar MM5 error estimate, which is $0.16 \mathrm{~m}$ w.e. $\mathrm{a}^{-1}$ along the entire traverse route, verifying the model prediction over the southeast ice sheet.

\subsection{Local topographic influence}

Accumulation rates are higher in topographic depressions (shaded bars in Fig. 3). Some combinations of wind redistribution of snow and water-vapor flux likely create this accumulation pattern. Over the Antarctic ice sheet, King and others (2004) showed that topography, snow precipitation, wind direction and speed resulted in significant snow redistribution that leads to high spatial variability in snow accumulation over distances as short as a few kilometers. The degree to which surface slope and accumulation rate correlate depends on how the GPR profile is oriented relative to the direction of the dominant wind (Spikes and others, 2004; Arcone and others, 2005a). In our study region, wind direction is essentially from $\sim 315^{\circ}$ (from the NASA-SE station), which is on average parallel to the GPR profile. But, for the last $10 \mathrm{~km}$ of the study transect (toward ACT10-C), the main wind direction may diverge up to $\sim 30^{\circ}$ from the GPR profile direction. This difference could explain amplitude differences and a slight phase shift between the accumulation rates and the surface-slope derivative (Fig. 6).

The second derivative of the surface-elevation profile yields the topographic curvature corresponding to the convexity or concavity of the terrain. Positive values represent concavity, where the terrain has a local depression, and negative values represent convexity, where the terrain has a local high (Fig. 6). The GPR-derived accumulation rates were detrended to remove the overall increasing accumulation rate along the studied transect. This convexity/ concavity index shows good agreement with the accumulation pattern. Higher accumulation correlates with concavity (positive values), with a correlation coefficient of $r^{2}=0.330$ (Fig. 6). 


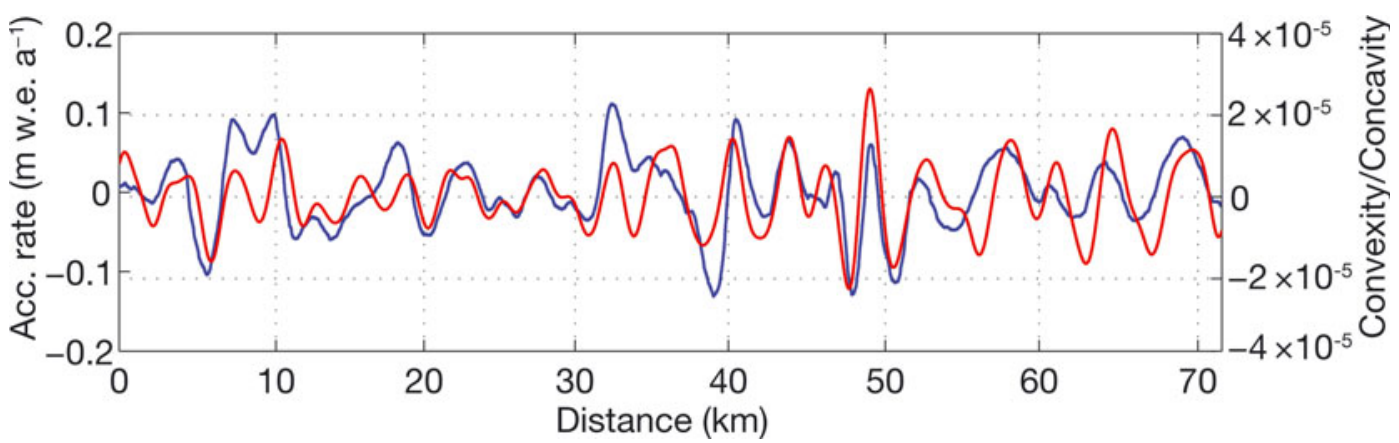

Fig. 6. Comparison between convexity/concavity index (red) and the detrended annual accumulation rate from the radar (blue) for the ACT10-A to ACT10-C transect. To calculate the convexity/concavity index, outliers were removed and a Gaussian smoothing function was applied, with $1 \sigma$ width of the Gaussian equal to $\sim 0.2 \mathrm{~km}(\sigma=70.5$ GPR horizontal traces).

Although the amplitude and local maxima/minima shifts between accumulation values and the convexity/concavity of the terrain do not correlate perfectly along the entire profile, it is generally true that the GPR-derived accumulation rates are lower if the surface is convex and higher if it is concave. This pattern is consistent with wind scouring from the tops of undulations and redeposition into adjacent depressions (or else there is less scouring in depressions). Here scouring refers to some combination of sublimation loss and wind redistribution.

\subsection{Temporal variability}

Temporal variability is investigated here using only the firn cores and is compared to the calibrated Polar MM5 (Table 1). We find that the GPR data do not clearly resolve annual accumulation rates because of the difficulty in tracking IRHs due to the increasing presence of ice layers as elevation decreases. The agreement between the averaged firn-core accumulation rates and the accumulation rates from calibrated Polar MM5 over corresponding time periods is characterized by correlation coefficients, $r^{2}$, ranging from 0.39 to 0.65 , and RMSE ranging from 0.11 to $0.25 \mathrm{~m}$ w.e. $\mathrm{a}^{-1}$ (Fig. 7). At the lowest-elevation core site, ACT10-A, the calibrated Polar MM5 underestimated the mean accumulation rate by $5 \%\left(0.06 \mathrm{~m}\right.$ w.e. $\left.\mathrm{a}^{-1}\right)$.

Atmospheric reanalysis and ice-core data indicate an increase in snow accumulation rates on the ice sheet since 1958 (Hanna and others, 2008; Box and others, 2013). However, no significant increasing temporal trends were identified over the length of our ACT-10 firn-core records.
The ACT-10 cores are $<40$ years in duration and seem dominated by high interannual variability (Fig. 7). An observation from Figure 7 reveals the presence of year 2003 as a strong positive accumulation anomaly, in ACT-10 firn cores. This high-accumulation year was related to persistent low atmospheric pressure on the southern tip of the ice sheet from September 2002 to April 2003 (Box and others, 2005). During this time period, large accumulation events are recorded by automatic weather stations, such as NASA-SE (located $\sim 55 \mathrm{~km}$ north of ACT10-C). For example, one event deposited $65 \mathrm{~cm}$ of fresh snow over 7 hours followed by strong winds compacting the snowpack down to $40 \mathrm{~cm}$ (Box and others, 2005). High-accumulation years like 2003 have implications for the following summer melt rates by maintaining a higher albedo, minimizing the impact of observed warming (e.g. Box and others, 2009) on increased melting.

The interannual variability observed in the firn cores is high, especially at the lowest-elevation site (ACT10-A) with a standard deviation of 0.373 mw.e. $\mathrm{a}^{-1}(\sim 30 \%$ of the mean). The calibrated Polar MM5 data at the corresponding gridcells have standard deviations of $0.152,0.123$ and 0.084 mw.e. $^{-1}$ for ACT10-A, ACT10-B and ACT10-C, respectively (Table 1$)$. This interannual variability in the southeast is large enough to significantly impact the total mass budget of the entire ice sheet, accounting for $\sim 30 \%$ of the ice-sheet total interannual variability in accumulation (Burgess and others, 2010).

However, the modeled accumulation rates show 50\% less variability compared to the firn cores. The Polar MM5
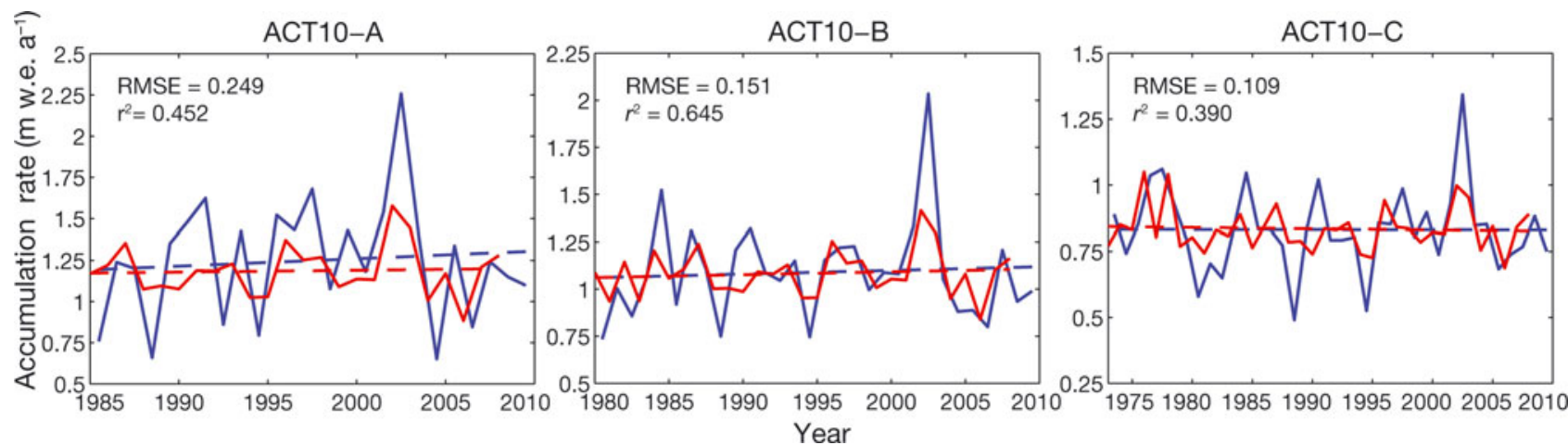

Fig. 7. Comparison of the temporal variation of accumulation between Polar MM5 (red) and firn cores (blue), for each core site, from low elevation to high elevation, ACT10-A, ACT10-B and ACT10-C, respectively. Dashed lines present a linear fit to the data for Polar MM5 (red) and firn cores (blue). There is a change in vertical scale between cores. 
interannual variability is lower than the firn-core observations because of the month-long model integration (Burgess and others, 2010), producing $\sim 30 \%$ lower interannual variability in Polar MM5 than in earlier configurations in which daily integrations are made (Box and others, 2006). In addition, this interannual variability discrepancy between the firn core and the model can be explained by the large model horizontal grid resolution compared to the point measurements of the firn cores. At the firn-core site, spatial variations due to wind redistribution result in incoherent 'glaciological noise' (Mosley-Thompson and others, 2001) in the firn-core data that is also not captured by a $24 \mathrm{~km}$ gridcell of Polar MM5. To reduce this incoherent noise, a common practice is to use multi-year average filters (Banta and McConnell, 2007). However, despite minimizing incoherent noise, these filters eliminate some of the highfrequency coherent signal, such as the presence of anomalous high-accumulation years (e.g. 2003). We find correlation coefficient values between firn cores of $r=0.84$ for ACT10-A vs ACT10-B; $r=0.75$ for ACT10-A vs ACT10-C; and $r=0.88$ for ACT10-B vs ACT10-C, all associated with $<10^{-5} p$-values, which are statistically significant (at $p<0.01$ ), for common time periods. These relatively high correlation coefficients $(r>0.75)$ between firn-core time series support the finding that both the firn cores and calibrated Polar MM5 capture a common climate.

Comparing a regional accumulation record with a largescale atmospheric circulation pattern is a commonly used process to identify precipitation source regions as well as understand how the observed interannual variability may affect the annual surface mass-balance estimates (e.g. Mosley-Thompson and others, 2005). The North Atlantic Oscillation (NAO), a dominant mode of regional atmospheric variability around Greenland, exerts a significant yet complex spatial and temporal influence on Greenland precipitation (e.g. Appenzeller and others, 1998; Hutterli and others, 2005; Mosley-Thompson and others, 2005; Banta and McConnell, 2007). The NAO is the difference in atmospheric pressure at sea level between the Icelandic-low pressure system and the Azores-high pressure system, and indicates changes in the intensity and direction of the North Atlantic storm tracks (Hurrell, 1995). The influence of the $\mathrm{NAO}$ on accumulation varies spatially and temporally for the Greenland ice sheet (Mosley-Thompson and others, 2005). Hutterli and others (2005) identified four regions over the Greenland ice sheet with distinct sources of accumulation variability, with only the western sector of the Greenland ice sheet presenting an inverse relationship with a NAO pattern. The other regions are affected by other largescale patterns (e.g. the southeast region, where accumulation is positively correlated with a high-pressure anomaly over the Greenland Sea).

Despite the short time-span of the cores (last 25-35 years), a comparison between the firn-core records and the December-March NAO index of Hurrell (1995), consistent with Box (2005), shows a negative correlation. Using this seasonal $\mathrm{NAO}$ index gives a $\sim 0.2$ higher correlation compared to using the annual NAO index. While the correlation coefficients are low $-r=-0.21$ for ACT10-A, $r=-0.25$ for ACT10-B, and $r=-0.38$ for ACT10-C - their $p$-values $(1-p$ ranging from 0.68 to 0.98 ) suggest that the captured signal is real. Mosley-Thompson and others (2005) demonstrated that the use of a temporal smoothing filter ( 5 year triangular filter) improved the correlation coefficients. Applying this filter to the ACT-10 firn-core data, we find a similar result with higher correlation coefficients: $r=-0.40$ for ACT10-A, $r=-0.33$ for ACT10-B, and $r=-0.59$ for ACT10-C. These low initial correlations may imply that the origin of moisture source in the southeast is not explained by the NAO alone.

\section{CONCLUSIONS}

The presence of three new annual accumulation records from our ACT-10 cores, as well as spatial accumulation rates from our GPR profile, provide necessary in situ measurements in the southeast sector of the Greenland ice sheet. Since the accumulation rate at our study site was greater than the vertical resolution of our GPR system, we expected to be able to track annual reflection horizons in our GPR profile. While this was possible at higher elevations along our transect, we found that it was not always possible at lower elevations because the presence of $>10 \mathrm{~cm}$ thick melt layers likely caused spatial discontinuity of IRHs.

The obtained in situ measurements of accumulation would contribute to further validation efforts and help reduce Greenland accumulation model uncertainties in the southeast sector, where accumulation rates are the highest on the ice sheet. Radar profiling along a $70 \mathrm{~km}$ transect between our firn cores indicates a 52\% $\left(\sim 0.43 \mathrm{mw}\right.$.e. $\left.\mathrm{a}^{-1}\right)$ increase in accumulation from the higher-elevation site (ACT10-C at $2350 \mathrm{~m}$ ) to the lower site (ACT10-A at $1830 \mathrm{~m}$ ). Maximum spatial variability estimated from the GPR, which is not captured by widely spaced single-point measurements such as firn cores, is found to be $23 \%$ (up to $0.24 \mathrm{~m}_{\text {w.e. }} \mathrm{a}^{-1}$ in this case) over distances as short as $7 \mathrm{~km}$. This shows that firn-core data alone may not be adequate to infer regional accumulation rates, as local topography and wind redistribution must be considered. Surface convexity is found to be a useful predictor of undulation-scale accumulation variability, with the highest local accumulation rates associated with local depressions (concavities).

No significant temporal trend exists in the firn-core data. The mean accumulation rates, of up to $1.26 \mathrm{~m}$ w.e. $\mathrm{a}^{-1}$, from the firn cores are in a good agreement with calibrated Polar MM5 output, but the amplitude of the interannual variability observed in firn cores is substantially reduced in the model output; interannual variability in the calibrated Polar MM5 is $\sim 50 \%$ less than measured in the firn cores. This is mainly due to a combination of 'glaciological noise' in the firn-core data, and the smoothing effect of using different model-integration strategies for Polar MM5. Further, the discrepancy in the interannual-variability amplitude, for the calibrated Polar MM5 and the firn cores, increases toward the coast as accumulation rates increase.

The three ACT-10 firn-core accumulation records, strongly inter-correlated $(r>0.75)$, are likely to be affected by a common climate. Initial comparisons between the accumulation records and seasonal NAO indices show low correlations, implying that the accumulation in southeast Greenland for recent decades is likely not controlled by the NAO alone.

\section{ACKNOWLEDGEMENTS}

We thank the chief editor, Gwenn Flowers, and the scientific editor, Catherine Ritz, for comments and handling of our manuscript. We thank Reinhard Drews and an anonymous reviewer for many insights and comments that 
substantially improved the manuscript. This work was supported by US National Science Foundation (NSF) Office of Polar Programs award ARC-090946 and ARC-0909499. Clément Miège is funded under the NASA Earth and Space Science Fellowship program. We thank Susan Zager and others at $\mathrm{CH} 2 \mathrm{M}$ HILL Polar Services for logistical assistance, and Terry Gacke and others at the Ice Drilling and Design Office (IDDO) for ice-drilling expertise and enthusiastic help with the expedition.

\section{REFERENCES}

Appenzeller C, Schwander J, Sommer S and Stocker TF (1998) The North Atlantic oscillation and its imprint on precipitation and ice accumulation in Greenland. Geophys. Res. Lett., 25(11), 1939-1942

Arcone SA, Spikes VB, Hamilton GS and Mayewski PA (2004) Stratigraphic continuity in $400 \mathrm{MHz}$ short-pulse radar profiles of firn in West Antarctica. Ann. Glaciol., 39, 195-200 (doi: 10.3189/172756404781813925)

Arcone SA, Spikes VB and Hamilton GS (2005a) Stratigraphic variation in polar firn caused by differential accumulation and ice flow: interpretation of a $400 \mathrm{MHz}$ short-pulse radar profile from West Antarctica. J. Glaciol., 51(174), 407-422 (doi: 10.3189/172756505781829151)

Arcone SA, Spikes VB and Hamilton GS (2005b) Phase structure of radar stratigraphic horizons within Antarctic firn. Ann. Glaciol., 41, 10-16 (doi: 10.3189/172756405781813267)

Bales RC, McConnell JR, Mosley-Thompson E and Csatho B (2001) Accumulation over the Greenland ice sheet from historical and recent records. J. Geophys. Res., 106(D24), 33 813-33 825 (doi: 10.1029/2001JD900153)

Bales RC and 8 others (2009) Annual accumulation for Greenland updated using ice core data developed during 2000-2006 and analysis of daily coastal meteorological data. J. Geophys. Res., 114(D6), D06301 (doi: 10.1029/2008JD010600)

Bamber JL, Ekholm S and Krabill WB (2001) A new, high-resolution digital elevation model of Greenland fully validated with airborne laser altimeter data. J. Geophys. Res., 106(B4), 6733-6745 (doi: 10.1029/2000JB900365)

Banta JR and McConnell JR (2007) Annual accumulation over recent centuries at four sites in central Greenland. J. Geophys. Res., 112(D10), D10114 (doi: 10.1029/2006JD007887)

Benson CS (1962) Stratigraphic studies in the snow and firn of the Greenland ice sheet. SIPRE Res. Rep. 70, 76-83

Box JE (2005) Greenland ice sheet surface mass-balance variability: 1991-2003. Ann. Glaciol., 42, 90-94 (doi: 10.3189/ $172756405781812772)$

Box JE and 7 others (2005) Extreme precipitation events over Greenland: consequences to ice sheet mass balance. In Preprints, Eighth Conference on Polar Meteorology and Oceanography. American Meteorological Society, San Diego, CA

Box JE and 8 others (2006) Greenland ice sheet surface mass balance variability (1988-2004) from calibrated Polar MM5 output. J. Climate, 19(12), 2783-2800 (doi: 10.1175/JCLI3738.1)

Box JE, Yang L, Bromwich DH and Bai L-S (2009) Greenland ice sheet surface air temperature variability: 1840-2007. J. Climate, 22(14), 4029-4049 (doi: 10.1175/2009JCLI2816.1)

Box JE and 10 others (2013) Greenland ice sheet mass balance reconstruction. Part I: net snow accumulation (1600-2009). J. Climate, 26(6) (doi: 10.1175/JCLI-D-12-00373.1)

Brown J, Harper J, Pfeffer WT, Humphrey N and Bradford J (2011) High-resolution study of layering within the percolation and soaked facies of the Greenland ice sheet. Ann. Glaciol., 52(59), 35-42

Burgess EW and 6 others (2010) A spatially calibrated model of annual accumulation rate on the Greenland Ice Sheet (1958-2007). J. Geophys. Res., 115(F2), F02004 (doi: 10.1029/ 2009JF001293)
Calanca P, Gilgen H, Ekholm S and Ohmura A (2000) Gridded temperature and accumulation distributions for Greenland for use in cryospheric models. Ann. Glaciol., 31, 118-120 (doi: 10.3189/172756400781820345)

Chen JL, Wilson CR and Tapley BD (2011) Interannual variability of Greenland ice losses from satellite gravimetry. J. Geophys. Res., 116(B7), B07406 (doi: 10.1029/2010JB007789)

Chen L, Johannessen OM, Wang $\mathrm{H}$ and Ohmura A (2011) Accumulation over the Greenland Ice Sheet as represented in reanalysis data. Adv. Atmos. Sci., 28(5), 1030-1038 (doi: 10.1007/s00376-010-0150-9)

Cogley JG (2004) Greenland accumulation: an error model. J. Geophys. Res., 109(D18), D18101 (doi: 10.1029/ 2003JD004449)

Dunse T, Eisen O, Helm V, Rack W, Steinhage D and Parry V (2008) Characteristics and small-scale variability of GPR signals and their relation to snow accumulation in Greenland's percolation zone. J. Glaciol., 54(185), 333-342 (doi: 10.3189/ 002214308784886207)

Eisen O, Wilhelms F, Nixdorf $\mathrm{U}$ and Miller H (2003) Revealing the nature of radar reflections in ice: DEP-based FDTD forward modeling. Geophys. Res. Lett., 30(5), 1218-1221

Eisen O, Wilhelms F, Steinhage D and Schwander J (2006) Improved method to determine radio-echo sounding reflector depths from ice-core profiles of permittivity and conductivity. J. Glaciol., 52(177), 299-310 (doi: 10.3189/172756506781828674)

Ettema J and 6 others (2009) Higher surface mass balance of the Greenland ice sheet revealed by high-resolution climate modelling. Geophys. Res. Lett., 36(12), L12501 (doi: 10.1029/ 2009GL038110)

Ettema J, Van den Broeke MR, Van Meijgaard E, Van de Berg WJ, Box JE and Steffen K (2010) Climate of the Greenland ice sheet using a high-resolution climate model: Part 1: evaluation. Cryos. Discuss., 4(4), 511-627 (doi: 10.5194/tc-4-511-2010)

Fettweis X (2007) Reconstruction of the 1979-2006 Greenland ice sheet surface mass balance using the regional climate model MAR. Cryosphere, 1(1), 21-40 (doi: 10.5194/tc-1-21-2007)

Hanna E, McConnell J, Das S, Cappelen J and Stevens A (2006) Observed and modelled Greenland Ice Sheet snow accumulation, 1958-2003, and links with regional climate forcing. J. Climate, 19(3), 344-358

Hanna E and 8 others (2008) Increased runoff from melt from the Greenland Ice Sheet: a response to global warming. J. Climate, 21(2), 331-341

Hanna E and 12 others (2011) Greenland Ice Sheet surface mass balance 1870 to 2010 based on Twentieth Century Reanalysis, and links with global climate forcing. J. Geophys. Res., 116(D24), D24121 (doi: 10.1029/2011JD016387)

Hines KM and Bromwich DH (2008) Development and testing of polar weather research and forecasting (WRF) model. Part I: Greenland ice sheet meteorology. Mon. Weather Rev., 136(6), 1971-1989

Hörhold MW, Kipfstuhl S, Wilhelms F, Freitag J and Frenzel A (2011) The densification of layered polar firn. J. Geophys. Res., 116(F1), F01001 (doi: 10.1029/2009JF001630)

Humphrey NF, Harper JT and Pfeffer WT (2012) Thermal tracking of meltwater retention in Greenland's accumulation area. J. Geophys. Res., 117(F1), F01010 (doi: 10.1029/ 2011JF002083)

Hurrell JW (1995) Decadal trends in the North Atlantic Oscillation: regional temperatures and precipitation. Science, 269(5224), 676-679 (doi: 10.1126/science.269.5224.676)

Hutterli MA, Raible CC and Stocker T (2005) Reconstructing climate variability from Greenland ice sheet accumulation: an ERA40 study. Geophys. Res. Lett., 32(23), L23712, 1-4 (doi: 10.1029/2005GL024745)

King JC, Anderson PS, Vaughan DG, Mann GW, Mobbs SD and Vosper SB (2004) Wind-borne redistribution of snow across an Antarctic ice rise. J. Geophys. Res., 109(D11), D11104 (doi: 10.1029/2003JD004361.) 
Kovacs A, Gow AJ and Morey RM (1995) The in situ dielectric constant of polar firn revisited. Cold Reg. Sci. Technol., 23(3), 245-256 (doi: 10.1016/0165-232X(94)00016-Q)

Leuschen C and Allen C (2011) IceBridge MCoRDS L2 Ice Thickness. NASA Distributed Active Archive Center, National Snow and Ice Data Center, Boulder, CO http://nsidc.org/data/ docs/daac/icebridge/irmcr2/index.html

Levitus S, Antonov JI, Boyer TP, Locarnini RA, Garcia HE and Mishonov AV (2009) Global ocean heat content 1955-2008 in light of recently revealed instrumentation problems. Geophys. Res. Lett., 36(7), L07608 (doi: 10.1029/2008GL037155)

Lucas-Picher P, Wulff-Nielsen M, Christensen JH, Aðalsgeirsdóttir G, Mottram R and Simonsen SB (2012) Very high resolution regional climate model simulations over Greenland: identifying added value. J. Geophys. Res., 117(D2), D02108 (doi: 10.1029/ 2011JD016267)

McConnell JR and Bales RC (2004) Investigation of chemical transfer processes between atmosphere and snow at South Pole. (NOAA/CMDL Summary Report 27) Climate Monitoring and Diagnostics Laboratory, National Oceanic and Atmospheric Administration, Boulder, CO, 153-154

McConnell JR and 6 others (2001) Annual net snow accumulation over southern Greenland from 1975 to 1998. J. Geophys. Res., 106(D24), 33,827-33,838

McConnell JR, Lamorey GW, Lambert SW and Taylor KC (2002) Continuous ice-core chemical analyses using inductively coupled plasma mass spectrometry. Environ. Sci. Technol., 36(1), 7-11 (doi: 10.1021/es011088z)

McConnell JR and 9 others (2007) 20th-century industrial black carbon emissions altered Arctic climate forcing. Science, 317(5843), 1381-1384 (doi: 10.1126/science.1144856)

Meehl GA and 12 others (2007) Global climate projections. In Solomon S and 7 others eds. Climate change 2007: the physical science basis. Contribution of Working Group I to the Fourth Assessment Report of the Intergovernmental Panel on Climate Change. Cambridge University Press, Cambridge, 747-845

Mosley-Thompson E and 8 others (2001) Local to regional-scale variability of annual net accumulation on the Greenland ice sheet from PARCA cores. J. Geophys. Res., 106(D24), 33 839-33 851

Mosley-Thompson ES, Readinger CR, Craigmile P, Thompson LG and Calder CA (2005) Regional sensitivity of Greenland precipitation to NAO variability. Geophys. Res. Lett., 32(24), L24707 (doi: 10.1029/2005GL024776)

Ohmura A and Reeh N (1991) New precipitation and accumulation maps for Greenland. J. Glaciol., 37(125), 140-148

Ohmura A, Calanca P, Wild M and Anklin M (1999) Precipitation, accumulation and mass balance of Greenland ice sheet. Z. Gletscherkd. Glazialgeol., 35(1), 1-20

Parry V and 6 others (2007) Investigations of meltwater refreezing and density variations in the snowpack and firn within the percolation zone of the Greenland ice sheet. Ann. Glaciol., 46, 61-68 (doi: 10.3189/172756407782871332)

Rae JGL and 14 others (2012) Greenland ice sheet surface mass balance: evaluating simulations and making projections with regional climate models. Cryosphere, 6(3), 2059-2113 (doi: 10.5194/tcd-6-2059-2012)

Rignot E and Mouginot J (2012) Ice flow in Greenland for the International Polar Year 2008-2009. Geophys. Res. Lett., 39(11), L11501 (doi: 10.1029/2012GL051634)

Rignot E, Velicogna I, Van den Broeke MR, Monaghan A and Lenaerts J (2011) Acceleration of the contribution of the Greenland and Antarctic ice sheets to sea level rise. Geophys. Res. Lett., 38(5), L05503 (doi: 10.1029/2011GL046583)

Sørensen LS and 7 others (2011) Mass balance of the Greenland ice sheet (2003-2008) from ICESat data - the impact of interpolation, sampling and firn density. Cryosphere, 5(1), 173-186 (doi: 10.5194/tc-5-173-2011)

Spikes VB, Hamilton GS, Arcone SA, Kaspari S and Mayewski P (2004) Variability in accumulation rates from GPR profiling on the West Antarctic plateau. Ann. Glaciol., 39, 238-244 (doi: 10.3189/172756404781814393)

Spikes VB, McConnell JR and Banta JR (2007) Annual layer mapping and net snowfall measurements across the southern Greenland ice sheet using shallow radar and ice cores. [Abstract C11A-0087] Am. Geophys. Union, Fall Meet.

Steffen K and Box J (2001) Surface climatology of the Greenland ice sheet: Greenland Climate Network 1995-1999. J. Geophys. Res., 106(D24), 33 951-33964 (doi: 10.1029/ 2001JD900161)

Van den Broeke $M$ and 8 others (2009) Partitioning recent Greenland mass loss. Science, 326(5955), 984-986 (doi: 10.1126/science.1178176) 